\title{
NovoSol Basal: pharmacokinetics of a novel soluble long acting insulin analogue
}

\author{
Stig Jørgensen, Allan Vaag, Liselotte Langkjær, Philip Hougaard, Jan Markussen
}

\begin{abstract}
Objective-To determine the courses of absorption and the interindividual and intraindividual variations in absorption of iodine-125 labelled Ultratard HM and NovoSol Basal injected subcutaneously.

Design-Open randomised crossover study. Each patient was tested during two study periods of five days each, during which he or she received a subcutaneous injection of either ${ }^{125} \mathbf{I}-\mathbf{N o v o S o l}$ Basal or ${ }^{125}$ I-Ultratard HM on four consecutive days. The aim was to detect a reduction in intraindividual standard deviation by a factor of two with a probability 0.95 , taking 0.05 as the level of significance. This required 24 degrees of freedom and led to the choice of four courses in each of eight patients.

Setting-Referrals to the diabetes research centre in Hvidøre, Copenhagen.
\end{abstract}

Patients-Eight insulin dependent (type I) diabetics with low or undetectable $C$ peptide concentrations who were receiving a multiple insulin injection regimen. One patient withdrew immediately after recruitment.

Interventions-After an overnight fast patients received $96 \mathrm{nmol}$ (16 IU insulin) of either ${ }^{125} \mathrm{I}$ NovoSol Basal or ${ }^{125}$ I-Ultratard $H M$ injected subcutaneously into the thigh. To ensure that the insulin entered the subcutaneous fat at the same depth, ultrasonography was performed on each patient before the first injection. A different injection site on the thigh was used each day for four days in order to facilitate monitoring of the disappearance of four different depots in each patient.

Main outcome measure-Residual activity at the injection site was measured roughly every two hours throughout the day. No radioactivity measurements were performed overnight (10 pm till $8 \mathrm{am})$. The residual radioactivity after the injection on the first day (upper right thigh) was recorded for five days, that after the injection on the second day (upper left thigh) for four days, after the injection on the third day (lower right thigh) for three days, and after the last injection (lower left thigh) for two days.

Results - NovoSol Basal was absorbed according to first order kinetics with a mean $\mathbf{t}_{50 \%}$ of $35 \cdot 3$ (SEM 1.4) hours; Ultratard HM was absorbed after a lag phase and the corresponding $t_{50 \%}$ was $25.5(2.5)$ hours. The intraindividual variations in $t_{50 \%}$ were significantly smaller with NovoSol Basal than with Ultratard HM $(18.4 \% v 44.5 \% ; \mathrm{p}<0.001)$. Interindividual variations, however, were not significantly different $(25.2 \% v 36.9 \% ; p=0.38)$. The total variation in $\mathbf{t}_{50 \%}$ was substantially smaller with NovoSol Basal than with Ultratard HM (20.3\% v $42 \cdot 8 \%$ ).

Conclusions-NovoSol Basal seems to be an appreciable advance over Ultratard $\mathrm{HM}$ as a soluble insulin preparation for obtaining reproducible
24 hour insulin concentrations in the blood after once daily injection.

\section{Introduction}

The optimal insulin treatment of insulin dependent (type I) diabetics is presumably a substitution regimen that mimics the pattern of insulin secretion of nondiabetics. This is characterised by a constant basal secretion during the 24 hours combined with a rapid increase after meals. ${ }^{1}$ Therapeutic strategies aimed at substituting insulin in this way are termed basal bolus regimens and entail multiple daily injections. Patients' acceptance of multiple injection regimens increased substantially after the introduction of NovoPen, which greatly facilitates the injection of meal related boluses of short acting insulin. ${ }^{2}{ }^{3}$ The efficacy of this treatment, however, is dependent on a constant and reproducible supply of a long acting insulin to cover the basal insulin requirements.

The absorption kinetics of short acting and longer acting insulins have been studied either directly by measuring the appearance of insulin in the blood or indirectly by monitoring the disappearance of iodine-125 labelled insulins from the injection sites. ${ }^{4-7}$ The indirect method is independent of the variations in endogenous insulin concentrations and insulin binding antibodies and so represents an important advantage compared with the direct method. It has, however, been argued that a variable proportion of insulin is degraded at the subcutaneous injection site. ${ }^{89}$ Other studies have shown good correlation between the disappearance of insulin from the injection site and the appearance in plasma, ${ }^{10} 11$ indicating that subcutaneous degradation seems to be minor.

Defined as the time elapsed until $50 \%$ of the injected radioactivity has disappeared, $\mathrm{t}_{50 \%}$ has been used as a parameter in describing absorption kinetics. ${ }^{5}$ The interpatient coefficient of variation in $t_{50 \%}$ is around $50-60 \%$ for clinical doses of regular (Actrapid), intermediate, or longer acting insulins (Semilente, Monotard, Insulin Leo Retard RI, Insulin Leo Mixtard RI, Ultratard HM). ${ }^{4712}$ More important clinically is the intrapatient variation in absorption. Only a few studies have addressed this problem. ${ }^{45712}$ The day to day variation in these studies was found to be of the same magnitude as the interpatient variation. This variation in absorption of both the short acting and long acting insulins is probably one of the causes of the day to day variation in glycaemic control observed in insulin treated diabetics. ${ }^{1}$

The longest acting human insulin used in general practice, Ultratard HM, has a $t_{50 \%}$ of around 1315 hours $^{6}$ when injected subcutaneously into the thigh. Certainly in some patients this duration is too short to provide basal insulin supplementation by injection once daily. ${ }^{14}{ }^{15}$ It has therefore been the goal to develop a protracted insulin preparation with the following 
properties: (a) a slow rate of absorption permitting once daily injection; $(b)$ a small day to day variation in absorption ensuring a stable and reproducible insulin concentration throughout the 24 hours; (c) solubility obviating the need for resuspension before injection, so making the preparation suitable for injection by pen devices. NovoSol Basal is the result of the first attempt to satisfy these requirements.

The physicochemical properties of NovoSol Basal are described in detail elsewhere. ${ }^{16}$ In brief, NovoSol Basal differs from human insulin in the following ways. Substitution of threonine in position B27 with arginine and amidation of the $\mathrm{C}$ terminal of the $\mathrm{B}$ chain have added two positive charges and thereby increased the isoelectric point of the insulin from $5 \cdot 4$ to $6 \cdot 8$. A further substitution of asparagine in position A21 with glycine renders the molecule stable in acid solution. NovoSol Basal is soluble in its formulation at $\mathrm{pH} 3 \cdot 0$. After injection, when the $\mathrm{pH}$ rises to about $7 \cdot 4$, NovoSol Basal crystallises. The resulting crystals are less than 5 um diameter.

This study compares the courses of absorption as well as the interindividual and intraindividual variations in absorption of ${ }^{125}$ I-NovoSol Basal and ${ }^{125}$ I-Ultratard HM after subcutaneous injection in diabetic patients

\section{Patients and methods}

All patients gave informed consent, and the protocol was approved by the local ethical committee. The study was carried out in accordance with the Declaration of Helsinki. A randomised crossover design was used and each patient was allocated to two study periods of five days separated by three weeks.

Seven type I diabetics (three men, four women) entered the study. Six patients had a fasting $\mathrm{C}$ peptide concentration $<0.05 \mathrm{nmol} / 1$ and one a fasting $\mathrm{C}$ peptide concentration of $0 \cdot 15 \mathrm{nmol} / 1$ (normal $0 \cdot 18$ $0.78 \mathrm{nmol} / \mathrm{l}$ ). All patients were of normal weight and had been diabetic for more than two years. All took regular human insulin (Actrapid HM) three times daily and isophane human insulin (Protaphane HM) at bedtime. Apart from simplex retinopathy no patient showed any signs of complications. None had lipodystrophy at injection sites. One further patient recruited for the study withdrew before it began and is excluded from the results.

The patients were admitted to hospital the evening before the investigation. Isophane insulin (Protaphane HM) was withdrawn and blood glucose concentrations stabilised between 4 and $10 \mathrm{mmol} / 1$ by means of small repeated doses of regular insulin (Actrapid HM) intramuscularly. Blood glucose values were measured as described. ${ }^{17}$ Each evening the patients received $200 \mathrm{mg}$ potassium iodide to prevent radioactive uptake by the thyroid.

${ }^{125}$ I labelled NovoSol Basal and ${ }^{125}$ I labelled Ultratard HM were each formulated to a concentration of $0.6 \mathrm{mmol} / 1$, equivalent on a molar basis to $100 \times 10^{3} \mathrm{IU}$ insulin $/ 1$, and to a radioactivity of $185 \mathrm{MBq} / \mathrm{l}$. Both preparations were labelled by a modification of an iodate method. ${ }^{18}$ The modification entailed using insulin as carrier instead of human albumin and a 30 times less degree of iodination than described. ${ }^{18}$ To ensure uniform subcutaneous injection ultrasonography was performed to identify two injection sites on each thigh with identical fat layers (5-9 mm).

On four consecutive mornings $96 \mathrm{nmol}$ of labelled preparation (16 IU insulin) was injected at the designated injection site. Labelled Ultratard HM was thoroughly resuspended, drawn into the syringe, and injected immediately. The correct injection depth was ensured by using a needle guard. The disappearance of radioactivity from the injection sites was monitored by four $5 \times 5 \mathrm{~cm}$ sodium iodide scintillation detectors enclosed in lead chambers and positioned roughly $10 \mathrm{~cm}$ above the skin. Radioactivity was measured about every two hours throughout the day. No radioactivity measurements were performed between $10 \mathrm{pm}$ and $8 \mathrm{am}$. At each time point data were accumulated every minute for five minutes and background radiation subtracted. The data were transferred direct to an IBM personal computer interfaced with the measuring equipment. Calculations presented below are based on the mean of measurements from each five minute period.

The residual radioactivity after the injections was recorded for five days after the first injection (upper right thigh), for four days after the second injection (upper left thigh), for three days after the third injection (lower right thigh), and for two days after the last injection (lower left thigh). On the last evenings of each study period patients were treated with their usual dose of isophane insulin. Throughout the study the patients received their usual dose of regular insulin at mealtimes.

Blood glucose concentrations were measured seven times a day according to normal hospital routine - that is, half an hour before each meal, one and a half hours after a meal, and at 2 am.

Statistical methods are detailed in the appendix.

\section{Results}

The mean blood glucose concentrations during the two study periods (estimated as the median of all blood glucose values during each period) were $10 \cdot 1 \mathrm{mmol} / 1$ with NovoSol Basal and $9.5 \mathrm{mmol} / 1$ with Ultratard HM. This difference was significant $(p=0.042)$. Figure 1 shows the individual disappearance curves as well as the mean curves for all 28 injections of each preparation. The initial radioactivity at the injection site was taken as $100 \%$ and all other measurements expressed in relation to this.

Figure 2 shows that the rate of absorption of NovoSol Basal was consistently about $2 \%$ of the residual insulin in the depot per hour, which was clear evidence of first order absorption kinetics. By contrast, Ultratard HM showed a lag phase in absorption, beginning at $2 \%$ of the residual insulin in the depot per hour and increasing to $9 \%$ after 35 hours.

The table shows the calculated $\mathrm{t}_{50 \%}$ of each preparation and the corresponding interpatient and intrapatient variations. The difference in intrapatient variation between the preparations was highly significant $(\mathrm{p}<0 \cdot 001)$, whereas interpatient variation differed non-significantly $(p=0 \cdot 38)$. The total variation was smaller with NovoSol Basal than with Ultratard HM $(20 \cdot 3 \%$ v $42 \cdot 8 \%)$.

Mean $t_{500^{\prime \prime}}$ values (and SEM) and mean intrapatient and interpatient variations with NovoSol Basal and Ultratard HM

\begin{tabular}{|c|c|c|c|}
\hline & NovoSol Basal & Ultratard $\mathrm{HM}$ & p Value \\
\hline $\mathrm{t}_{50^{\prime \prime},}$ (Hours) (SEM) & $35 \cdot 3(1 \cdot 4)$ & $25 \cdot 5(2 \cdot 5)$ & $<0.001$ \\
\hline Intrapatient variation $(\%)$ & $18 \cdot 4$ & $44 \cdot 5$ & $<0 \cdot 001$ \\
\hline Interpatient variation $(\%)$ & $25 \cdot 2$ & $36 \cdot 9$ & $0 \cdot 38$ \\
\hline Overall variation $(\%)$ & $20 \cdot 3$ & $42 \cdot 8$ & \\
\hline
\end{tabular}

For each preparation and each hour the interindividual and intraindividual variability in the interpolated residual activity were calculated and compared. Interindividual variability was not significantly greater than intraindividual variability except with Ultratard HM 73-83 hours after injection $(p=0.03$ to 0.05 ). Owing to the large number of tests performed and the few courses ${ }^{14}$ in this period the interindividual variability was considered to be of the same magnitude as the intraindividual variability. 
Case 1
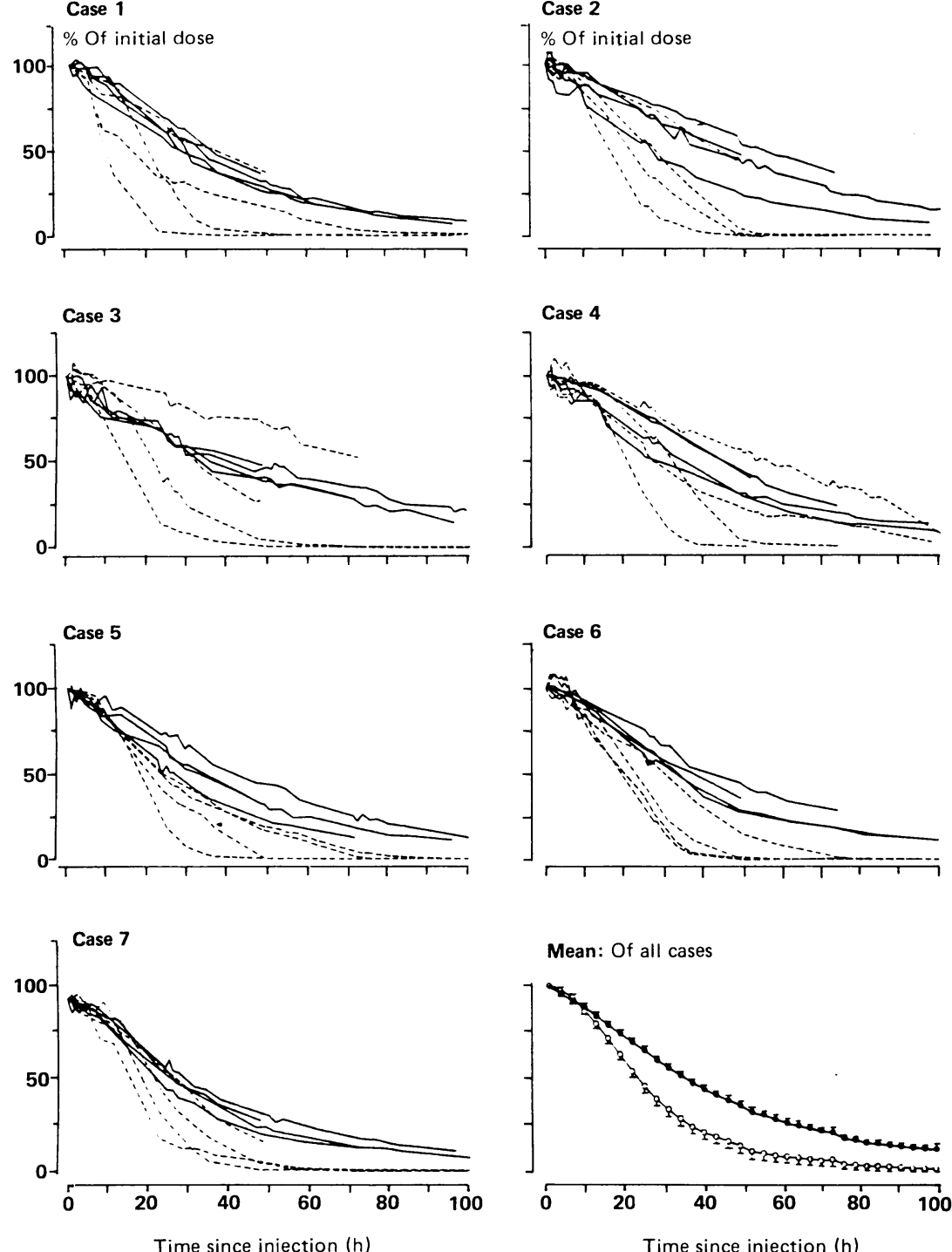

FIG 1-Individual curves of residual radioactivity at injection sites expressed as percentage of initial doses of NovoSol Basal (-) and Ultratard HM (---). Mean values of residual activity (bottom right) expressed as percentage of doses of NovoSol Basal (•) and Ultratard HM(O). SEM (bars) calculated as though all courses were independent

Figure 3 shows the pooled intrapatient variation in residual percentage as a function of the average residual percentage. The intrapatient variation with NovoSol Basal was significantly smaller $(\mathrm{p}<0.05)$ than with Ultratard HM from when $87 \%$ remained at the depot (that is, after $13 \%$ had been absorbed). The difference was significant $(\mathrm{p}<0.01)$ from when $84 \%$ remained at the depot.

The site of injection did not influence the rate of absorption of either preparation (NovoSol Basal, $\mathrm{p}=0 \cdot 12$; Ultratard $\mathrm{HM}, \mathrm{p}=0 \cdot 16$ ).

\section{Discussion}

In this study NovoSol Basal, a soluble long acting insulin analogue, showed improved absorption characteristics in comparison with Ultratard HM. Regardless of whether the coefficient of variation in $\mathrm{t}_{50^{\%}}$ or the pooled intraindividual variation in residual percentage as a function of average residual percentage was used, NovoSol Basal showed significantly less intrapatient variation compared with Ultratard HM.

The terms $t^{1 / 2}$ and $t_{50^{\circ}}$ are often incorrectly used synonymously. For all preparations $t_{50 \%}$ may be defined as the time elapsed when half of the radioactive depot has disappeared from an injection site. If the elimination follows first order kinetics $t^{1 / 2}$ is defined as $\ln 2 / k_{1}$, where $k_{1}$ is the rate constant. As this was the case for NovoSol Basal the calculated $t \frac{1}{2}$ of 35 hours describes the whole absorption phase. The term $t^{1 / 2}$ does not completely describe the actual course of absorption of Ultratard HM owing to the presence of a lag phase and the absence of first order absorption and hence $\mathrm{t}_{50 \%}$ is used.

In previous studies of short acting and long acting insulin preparations given subcutaneously it has been assumed that the injection technique used ensures subcutaneous delivery. Recent studies using computed tomography to measure the thickness of the subcutaneous fat laver, however, have shown great variation at the various injection sites and also established that diabetics often have very thin fat layers, especially at the generally recommended injection sites on the thigh. ${ }^{19}{ }^{20}$ The fat layer over the thighs of all our patients was $<9 \mathrm{~mm}$, suggesting that even with modern $12 \mathrm{~mm}$ needles a large proportion of all insulin injections are given intramuscularly.

The differences in absorption of insulins given subcutaneously and intramuscularly have not been investigated for long acting preparations. Results with short acting preparations, however, are controversial; some studies failed to detect any significant differences, ${ }^{12} 21.23$ whereas others showed more rapid absorption with intramuscular injection. ${ }^{54} \mathrm{~A}$ possible explanation of the great interpatient variations might be that injections intended to be subcutaneous were in some patients inadvertently given intramuscularly. This is supported by the fact that the $t_{50 \%}$ of Ultratard HM in this study after controlled subcutaneous injection was 25 hours as compared with a previously reported $t_{50 \%}$ of 15 hours. ${ }^{6}$

In other studies with only one injection of each preparation in each patient it was not possible to estimate the intraindividual or interindividual variation but only the total variation, which includes both. In our study both can be estimated as well as the total

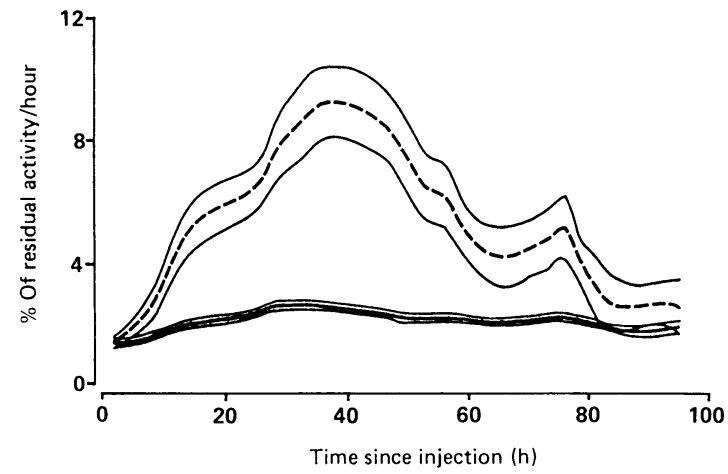

FIG 2-Mean (and SEM) rates of absorption of NovoSol Basal $(-)$ and Ultratard HM (-.-) expressed as percentage of residual activity per hour. SEM calculated as though all courses were independent

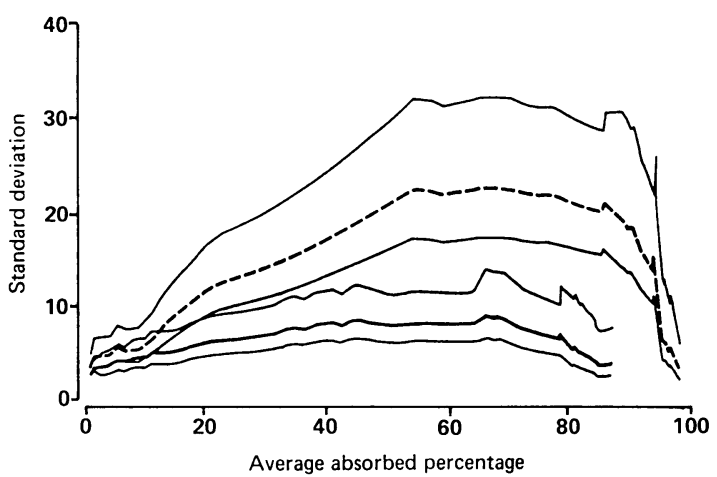

FIG 3-Pooled intraindividual standard deviations in absorbed percentage of NovoSol Basal (-) and Ultratard HM (--.) expressed as function of average absorbed percentage (with $95 \%$ confidence intervals). Confidence intervals based on $\chi^{2}$ distribution. Variability was significantly smaller with NovoSol Basal than with Ultratard HM after $13 \%$ of depot had been absorbed 
variation, which was $20 \cdot 3 \%$ with NovoSol Basal and $42 \cdot 8 \%$ with Ultratard $H M$. The total percentage variation with Ultratard $\mathrm{HM}$ was close to the value (46.8\%) reported by Hildebrandt et al. ${ }^{6}$

Clinical experience has established the difficulty of transferring crystalline Ultratard HM from phial to syringe in a reproducible manner. The Ultratard HM crystals are large (about $25 \mu \mathrm{m}$ diameter) and therefore tend to precipitate in the phial. If the preparation is not thoroughly shaken and injected immediately there is a risk of injecting different amounts of the insulin. This may have a fundamental influence on the observed variation in absorption, and the injection technique used in this study was therefore designed to overcome the problem.

The study on four consecutive days was specifically designed to mimic clinical conditions. Statistical evaluation showed no significant influence of injection site on the courses of absorption. Thus differences in absorption between the two insulin preparations can only be interpreted as differences in absorption characteristics.

Normoglycaemia is the desired end point of all insulin treatment, but a main problem with this strategy is the increased risk of hypoglycaemic episodes. A very small day to day variation in absorption of long acting insulin will diminish this risk by reducing the daily fluctuations in the basal insulin concentration.

We can only speculate about the mechanism of the low variability in absorption of NovoSol Basal. One possibility is that absorption from the injected depot into the blood system is mainly dependent on its physicochemical properties and less dependent on factors such as blood flow, temperature, zinc ions, etc. Another possibility is that injecting a solution renders the insulin evenly distributed in the injected volume, whereas crystals after injection may be trapped in tissue pores and filtered off, thus concentrating in these sites.

The clinical importance of the observed $t^{1 / 2}$ of $35 \cdot 3$ hours for NovoSol Basal is that the prolonged and consistent rate of absorption offers the possibility of achieving a stable and reproducible basal plasma insulin concentration by means of a single daily injection. A therapeutic steady state in which the amount of insulin absorbed is identical with the amount injected takes at least 175 hours to achievethat is, five to seven times the $t^{1 / 2}-$ when NovoSol Basal is given as a once daily fixed dose. This state can be reached faster if, say, a double dose is injected on the first day. Furthermore, the long $t^{1 / 2}$ requires that treatment with NovoSol Basal must be given for about a week before metabolic control can be evaluated. The modest interpatient variation with NovoSol Basal means that once clinicians are familiar with the comparatively long $t^{1 / 2}$ they can disregard possible intrapatient variations. The significant difference in mean blood glucose concentrations between the two treatment periods was irrelevant in this study, which was not designed to evaluate differences in the metabolic effects. The investigation periods were too short to achieve a therapeutic steady state, and several patients received small individual doses of regular insulin during the day.

\section{Conclusion}

Probably because of the physicochemical properties of NovoSol Basal it has remarkably better absorption characteristics than Ultratard $\mathrm{HM}$, which at present is the longest acting human insulin commercially available. The improved qualities of NovoSol Basal are manifested by a significantly smaller intrapatient variation in absorption. The absorption of NovoSol
Basal follows first order kinetics with a $t_{50 \%}$ of 35.3 hours. Ultratard HM has a significantly shorter $\mathrm{t}_{50 \%}$ of $25 \cdot 5$ hours

Soluble, long acting NovoSol Basal seems suitable for providing a stable, reproducible 24 hour basal plasma insulin concentration after a single daily injection.

We are indebted to Mrs Lisbet Pedersen for invaluable work during the practical phase of the study and to Dr Ulla Dahl Larsen for preparing the labelled preparations. We also thank Mrs Kathleen Larsen for reviewing the manuscript and the staff at Hvidøre Hospital for their help.

\section{Appendix}

To demonstrate first order kinetics the absorption rate relative to the residual insulin in the depot was calculated by means of kernel function smoothing by using a band width of 10 hours. ${ }^{25}$ Each course was estimated separately based on the time of measurements and the logarithm of the residual percentage.

Interpatient and intrapatient variations in $t_{50 \%}$ for both preparations were analysed by two one way variance component models of the log transformed $t_{50 \%}$. Intrapatient variation in the log transformed data was compared within the two preparations by an $\mathrm{F}$ test. Interpatient and intrapatient variations between preparations were compared by an $\mathrm{F}$ test.

Describing variation in absorption by the coefficient of variation in $\mathrm{t}_{50 \%}$ is insufficient because it depends on only one point in time and the result is strongly dependent on the mean absorption course. Thus it is difficult to compare two preparations when their mean absorption courses are different. A somewhat better approach is to describe the variation in the amount of insulin in the depot.

For each course of absorption the residual percentage of insulin is found every hour by linear interpolation - say, $\mathbf{x}_{\mathrm{ijk}}$ for preparation $i$, patient $j$, and course $k$ at one hour after injection. The number of courses for the patient and preparation at the time is $n_{i j l}$. At each time point the pooled intraindividual standard deviation of residual percentages is found. The square of this is $\mathrm{s}_{\mathrm{il}}^{2}=\sum_{\mathrm{i}} \Sigma_{\mathrm{k}}\left(\mathrm{x}_{\mathrm{ijkl}}-\mathrm{x}_{\mathrm{ij} .1}\right)^{2} / \Sigma_{\mathrm{j}}\left(\mathrm{n}_{\mathrm{ijl}}-1\right)$, where $x_{i j .1}$ is the average studied as a function of the residual amount averaged over patients, $x_{i}, 1$. The preparations are compared by the $\mathrm{F}$ test for variance homogeneity at time points different for the two preparations but with the same residual activity. In practice this is done by linear interpolation of $\mathrm{s}^{2}$ il on $\mathrm{x}_{\mathrm{i}} \ldots$. The choice of the one hour grid for interpolation is not critical to the conclusion.

Significance of the injection site with regard to absorption was determined by two two way analyses of variance of the $\log$ transformed $\mathrm{t}_{50 \%}$. Corresponding blood glucose concentrations were analysed by a paired $t$ test. p Values $<0.05$ were taken as significant.

I Eaton RP, Allen RC, Schade DS, Standefer JC “Normal" insulin secretion: the goal of artificial insulin delivery systems? Diabetes Care 1980;3:270-3.

2 Berger AS, Saurbrey N, Kühl C, Villumsen J. Clinical experience with a new device that will simplify insulin injections. Diabetes Care 1985;8:73-6.

3 Jefferson IG, Marteau TM, Smith MA, Baum JD. Multiple injection regimen using an insulin injection pen and pre-filled cartridged soluble human insulin in adolescents with diabetes. Diabetic Med 1985;2:493-7.

4 Lauritzen T, Faber OK, Binder C. Variation in ${ }^{12} I$-insulin absorption and blood glucose concentration. Diabetologia 1979;17:291-5.

Binder C. Absorption of injected insulin: a clinical-pharmacological study. Acta Pharmacologica et Toxicologica 1969;27(suppl 2):1-84

6 Hildebrandt P, Berger A, Volund Aa, Kühl C. The subcutaneous absorption of human and bovine ultralente insulin formulations. Diabetic Med 1985;2: of hum

7 Kolendorf K, Aaby P, Westergaard S, Deckert T. Absorption, effectiveness and side effects of highly purified porcine $\mathrm{NPH}$-insulin preparations $\left(\mathrm{Leo}^{\mathrm{R}}\right)$. and side effects of highly purified porcine

8 Berger M, Halban PA, Girardier L, Seydoux J, Offord RE, Renold AE. Absorption kinetics of subcutaneously injected insulin. Diabetologia Absorption Kinc $1979 \cdot 17 \cdot 97-9$.

9 Berger M, Cüppers HJ, Hegner H, Jörgens V, Berchtold P. Absorption kinetics and biologic effects of subcutaneously injected insulin preparations. Diabetes Care 1982;5:77-91.

10 Lauritzen T, Pramming S, Gale EAM, Deckert T, Binder C. Absorption of isophane (NPH) insulin and its clinical implications. Br Med $\mathcal{F}$ 1982;285: $159-62$.

1 Lauritzen T, Pramming S, Deckert T, Binder C. Pharmacokinetics of continuous subcutaneous insulin infusion. Diabetologia 1983;24:326-9.

12 Galloway JA, Spradlin CT, Nelson RL, Wentworth SM, Davidson JA, Swarner JL. Factors influencing the absorption, serum insulin concentration, and blood glucose responses after injections of regular insulin and various insulin mixtures. Diabetes Care 1981:3:366-76.

13 Molnar GD, Reynolds C. Diurnal glucose variability and hormonal regulation. Horm Metab Res 1977; suppl 7:148-57. 
1t Saner B, Fankhauser S. Lltratard HM, ein neues Humaninsulin. Vorteil gegenuiber den bisherigen Präparaten? Schaciz. Hed Wochenschr 1986;116: $116-9$.

15 Francis AJ, Hanning I, Alberti KGMM. Human ultralente insulin a comparison with porcine lente insulin as a twice-dails insulin in insulin-dependent diabetic patients with fasting hyperglycaemia. Diabetes Res 1986:3:263-8

16 Markussen J, Diers I, Hougaard P, et al. Soluble, prolonged-acting insulin derivatives. III. Degree of protraction, cystallizability and chemical stability of insulins substituted in positions A21, B13, B23, B27 and B30. Protein Engineering 1988:2:157-66.

17 Andersen I, Hannibal S. Analytical and economical optimization of a glucose method with immobilized enzymes. Fournal of Automated Chemistry 1983;5: $188-92$.

18 Jorgensen KH, Larsen UD. Homogeneous mono-"'I insulins. Preparation

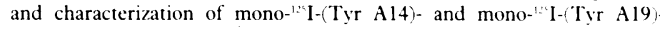
insulin. Diabetologia 1980;19:546-54.

19 Frid A, Linde B. Where do lean diabetics inject their insulin? A study using computed tomography. Br Med f 1986;292:1638.
20 Frid A, Gunnarsson R, Günter P, Linde B. Effects of accidental intramuscular injection on insulin absorption in IDI) M. Diabetes Care 1988;11:41-5.

21 Moore EW. Mitchell ML. Chalmers TC. Variability in absorption of insulin- $\mathrm{I}^{1 / 1}$ in normal and diahetic subjects after subcutaneous and intramuscular injection. $\mathcal{F}$ Clin Ineest 1959;38:1222-7.

22 Shahshahani MN, Kitabchi AE Glucose-lowering effect of insulin by differen routes in obese and lean nonketotic diabetic patients. $f$ Clin Endocrinol Metab 1978:47:34-40.

23 Owens DR, Hayes TM, Alberti KGMM, et al. Comparative study of subcutaneous, intramuscular, and intravenous administration of human insulin. Lancet 1981;ii:118-21.

24 Nora JJ, Smith DW, Cameron JR. The route of insulin administration in the management of diabetes mellitus. F P'ediatr 1964;64:547-51.

25 Hougaard P, Plum A, Ribel U. Kernel function smoothing of insulin absorption kinctics. Biometrics (in press).

\title{
Ear, nose, and throat symptoms in subacute Wegener's granulomatosis
}

\author{
D P D'Cruz, E Baguley, R A Asherson, G R V Hughes
}

Lupus Arthritis Research

Unit,

Rayne Institute,

St Thomas's Hospital,

London SE1 7EH

D P D'Cruz, MRCP, registrar

E Baguley, MRCP, senior registrar

R A Asherson, MD, honorary consultant physician

G R V Hughes, MD, head of

Lupus Arthritis Research Unit

Correspondence to: Dr Hughes.

Br.Med. 7 1989:299:419-22

\begin{abstract}
The standard description of Wegener's granulomatosis emphasises renal failure and thus a distorted impression may be given. Subacute and even chronic cases occur, and in these patients the presentation is varied and often insidious, leading to delay in diagnosis. Twenty two such patients (13 women and nine men) with a mean age of 44 years were seen in our connective tissue disease clinic. The mean duration of symptoms before diagnosis was 3.6 years and the mean duration of disease 5.9 years (19 years in one patient). All patients had malaise and ear, nose, and throat symptoms, and most had joint pains. Impaired renal function was seen in seven patients only. Tissue biopsy was diagnostic in half of the patients, and appreciably high titres of antineutrophil cytoplasmic antibodies were detected in only nine of 18 patients in whom these were measured. The most useful investigations were neutrophil counts, chest radiographs, and computed tomography of the sinuses and orbits. The most effective treatment was with intravenous pulses of cyclophosphamide. No deaths occurred. At the time of writing two patients were in remission and no longer being treated and 18 patients were in partial remission on continued treatment.
\end{abstract}

Patients with subacute forms of Wegener's granu- lomatosis present with a variety of clinical features and the insidious presentation often leads to delay in diagnosis. A history of ear, nose, and throat symptoms was universal in our patients.

\section{Introduction}

The classical presentation of Wegener's granulomatosis with vasculitis of the upper and lower respiratory tracts together with fulminant glomerulonephritis and systemic vasculitis is well recognised. ${ }^{12}$ By contrast, some patients present to rheumatology departments with features that are less dramatic, and the diagnosis is often delayed. We studied 22 patients who presented over the past three years at our connective tissue disease clinic with subacute and chronic Wegener's granulomatosis

\section{Patients, methods, and results}

Of the 22 patients, 14 had been referred by other centres in the United Kingdom, five were from our health region, and three had been referred from other countries. All were initially assessed as either inpatients or outpatients by standard clinical and laboratory methods. The diagnosis of Wegener's granulomatosis was based on the clinical findings and

TABLE I-Clinical features and results of laboratory tests in 22 patients with Wegener's granulomatosis

\begin{tabular}{|c|c|c|c|c|c|c|c|c|c|c|c|c|}
\hline $\begin{array}{l}\text { Case } \\
\text { No }\end{array}$ & Sex & $\begin{array}{l}\text { Ear, nose, } \\
\text { and throat } \\
\text { symptoms }\end{array}$ & $\begin{array}{c}\text { Radiography } \\
\text { of ear, nose, } \\
\text { and throat }\end{array}$ & $\begin{array}{l}\text { Pulmonary } \\
\text { symptoms }\end{array}$ & $\begin{array}{l}\text { Pulmonary } \\
\text { radiography }\end{array}$ & $\begin{array}{c}\text { Eye } \\
\text { symptoms }\end{array}$ & $\begin{array}{l}\text { Renal } \\
\text { disease }\end{array}$ & $\begin{array}{l}\text { Systemic } \\
\text { features }\end{array}$ & Histology & $\begin{array}{l}\text { Antineutrophil } \\
\text { cytoplasmic } \\
\text { antibody }\end{array}$ & Neutrophilia & $\begin{array}{l}\text { High erythrocyte } \\
\text { sedimentation } \\
\text { rate }\end{array}$ \\
\hline 1 & $M$ & + & + & + & + & + & & + & Insufficient tissue & Negative $^{\star}$ & - & + \\
\hline 2 & $M$ & + & - & - & + & + & & + & Masal positive & Positive $^{\star}$ & + & + \\
\hline 3 & $\mathrm{~F}$ & + & + & + & - & + & & + & Nasal:non-specific necrosis & Positive & + & + \\
\hline 4 & $\mathrm{~F}$ & + & - & + & + & + & + & + & $\begin{array}{l}\text { Lung positive } \\
\text { L }\end{array}$ & Negative $^{\star}$ & + & + \\
\hline 5 & $\mathrm{~F}$ & + & + & - & - & + & + & + & Nasal+renal positive & Negative & - & + \\
\hline 6 & $\mathrm{~F}$ & t & + & - & - & - & & + & Nasal positive & Negative & - & - \\
\hline 7 & $\mathrm{~F}$ & + & + & + & + & - & & + & Records missing & & - & - \\
\hline 8 & $\mathrm{~F}$ & + & - & - & - & + & & + & Negative & Not done & + & + \\
\hline 9 & M & + & + & + & + & + & & + & Nasal positive & Positive* & + & + \\
\hline 10 & $\mathrm{~F}$ & + & + & + & + & + & & + & Nasal positive & Positive ${ }^{\star}$ & + & + \\
\hline 11 & $\mathrm{~F}$ & + & + & + & + & - & & + & Lung positive & Not done & + & + \\
\hline 12 & $M$ & + & + & + & + & + & & + & Lung positive & Positive & + & + \\
\hline 13 & $\mathrm{~F}$ & + & - & + & + & + & & + & Nasal positive & Positive & + & + \\
\hline 14 & $\mathrm{~F}$ & t & + & + & + & + & & + & Lung, nose, skin positive & Positive strong & + & + \\
\hline 15 & M & + & + & + & - & + & + & + & Ear and renal positive & Not done & + & + \\
\hline 16 & $\mathrm{~F}$ & + & + & + & - & + & & + & Non-diagnostic giant cells & Positive & + & + \\
\hline 17 & $\mathrm{~F}$ & + & + & - & & + & + & + & Skin positive & Negative & + & + \\
\hline 18 & M & + & + & + & - & + & & + & Not done & Negative & + & + \\
\hline 19 & $\mathrm{~F}$ & + & + & + & - & + & & + & Nasal positive & Negative & - & + \\
\hline 20 & $M$ & + & Not done & + & + & - & t & + & Renal positive & Negative $^{\star}$ & + & + \\
\hline 21 & $M$ & + & - & + & + & - & + & + & Skin and renal positive & Positive strong & + & + \\
\hline 22 & $M$ & + & - & + & + & + & & + & Sternal mass positive & Negative $^{\star}$ & - & + \\
\hline
\end{tabular}

